\title{
In-Vivo nutritional and toxicological evaluation of nano iron fortified biscuits as food supplement for iron deficient anemia
}

\begin{abstract}
Iron deficiency anemia (IDA) is a global nutritional metabolic disorder affecting majority of healthy people rather than those suffering from chronic diseases. The main reason for IDA is not the existence quantity of iron in food but its bioavailability form. The present work represents new modality to increase the intestinal absorptivity of iron through biosynthesis of biocompatible iron nanoparticles $\left(\mathrm{Fe}_{3} \mathrm{O}_{4}\right)$ capped with vitamin $\mathrm{C}$. Intestinal villi will absorb the nano particles as Vitamin $\mathrm{C}$ not as iron because Iron particles are coated with Vitamin $\mathrm{C}$ in order to overcome the limited absorptivity of iron in gut. Biocompatible magnetite nanoparticles $\left(\mathrm{Fe}_{3} \mathrm{O}_{4}\right)$ of size range $20 \pm 5 \mathrm{~nm}$ were synthesized and characterized by Transmission Electron Microscope (TEM) and X-Ray Diffraction (XRD). Iron Deficient anemic rats were treated with an iron free basal diet for long period and hematological indices were tested for establishing the anemic state. Three levels Nano Iron Fortified Biscuits (10 ppm, $30 \mathrm{ppm}$ and $60 \mathrm{ppm}$ iron) were prepared and one level of Ferric Chloride $\left(\mathrm{FeCl}_{3}\right)$ fortified biscuits, $10 \mathrm{ppm}$, in addition to untreated control group nourished iron free basal diet. Results reveals that, the nano iron form promoted the growth rate and increased the nutritional quality of protein and enhance the erythropoiesis process where Hemoglobin concentration increased from $9.9 \pm 1.2 \mathrm{~g} / \mathrm{dl}$ to be $14.6 \pm 1.1 \mathrm{~g} / \mathrm{dl}, 16.7 \pm 1.6 \mathrm{~g} / \mathrm{dl}$ and 18.2 $\pm 2.1 \mathrm{~g} / \mathrm{dl}$ For the tree levels of $10 \mathrm{ppm}, 30 \mathrm{ppm}$ and $60 \mathrm{ppm}$, respectively. While for RBCs count increased to be $6.7 \pm 1.4 \times 10^{6} / \mathrm{mm}^{3}, 7.3 \pm 1.6 \times 10^{6} / \mathrm{mm}^{3}$ and $7.8 \pm 1.8 \times 10^{6} /$ $\mathrm{mm}^{3}$, respectively. Toxicological evaluation show no apparent toxicological sings with no mortality. Based on the Histopathological and biochemical examinations The present work recommend the use of $10 \mathrm{ppm}$ Nano iron fortified biscuits for mild iron deficiency anemia and the $30 \mathrm{ppm}$ level for more sever one to manage and control Iron deficient anemia and extra toxicological testing are still required.
\end{abstract}

Volume 3 Issue I - 2016

\author{
Taher A Salaheldin,' Eman M Regheb ${ }^{2}$ \\ 'Nanotechnology and Advanced Materials Central Lab, \\ Agriculture Research Center, Egypt \\ ${ }^{2}$ Regional Center for Food \& Feed,Agriculture Research Center, \\ Egypt
}

Correspondence: Taher A Salaheldin, Nanotechnology \& Advanced Materials Central Lab, Agriculture Research Center, Giza, Egypt Email TIsalah@hotmail.com

Received: December 04, 2015 | Published: January 27, 2016

Keywords: Nano iron, Fortification, Nutrition, Toxicology, Anemia

Abbreviations: IDA, Iron Deficiency Anemia; TEM, Transmission Electron Microscope; XRD, X-Ray Diffraction; NAMCL, Nanotechnology and Advanced Materials Central Lab; ICP, Inductivity Coupled Plasma; NPU, Net Protein Utilization; BV, Biological Value; TD, True Digestibility; AST, Aspartate Transaminase; ALT, Alanine Transaminase; ANOVA, Analysis of Variance; HB, Hemoglobin Concentration; RBCs, Red Blood Cells Count; CV, Central Vein; H, Surrounding Hepatocytes; W, White Pulp Lymphoid Follicles; R, Red Pulps with Sinusoids; P, Pericardium; M, Myocardium; B, Bronchus; V, Air Alveoli; BV, Blood Vessel; RT, Renal Tubules; G, Glomeruli

\section{Introduction}

Iron deficiency anemia (IDA) is one of the most common global nutritional deficiency health disorder involving nearly about one-third of world population, the great majority resident in the developing country and the risk is highest for children and women of childbearing age. ${ }^{1-4}$

The health consequences for women suffering from iron deficiency during pregnancy including lower birth weight, impaired psychomotor development in infancy with effects on later cognitive function, an increased prevalence and duration of upper respiratory infections in children, and reduced physical work performance at all ages. ${ }^{5-8}$ Oral iron supplementation is still the major route for treatment IDA although it is not well tolerated by all patients and intestinal iron absorption is not always adequate. ${ }^{9,10}$
Food fortification is considered to be the most cost-effective strategy for combating nutritional iron deficiency in population groups that buy one or more commonly eaten food items. It is an attractive strategy because consumer compliance is ensured; it can be both inexpensive to initiate and sustainable. ${ }^{11}$ Frequently used forms of iron in supplements include ferrous and ferric iron salts, such as ferrous sulfate, ferrous gluconate, ferric citrate, and ferric sulfate. ${ }^{11-12}$ Nowadays several iron nanoparticles formulation were used to replace the frequently used iron salt in treatment IDA with great efficiency and lower side effects. ${ }^{13,14}$ The present work represents new modality to increase the intestinal absorptivity of iron through biosynthesis of biocompatible iron nanoparticles $\left(\mathrm{Fe}_{3} \mathrm{O}_{4}\right)$ capped with vitamin C. Intestinal villi will absorb the nano particles as Vitamin $\mathrm{C}$ not as iron because Iron particles are coated with Vitamin $C$ in order to overcome the physiological limited absorptivity of iron in gut. In-vivo nutritional and toxicological evaluation was done during the designed experiment period of five weeks.

\section{Materials and methods}

\section{Preparation of biocompatible iron nanoparticles:}

$20 \pm 5.0 \mathrm{~nm}$ size biocompatible iron nanoparticles in form of magnetite nanoparticles $\left(\mathrm{Fe}_{3} \mathrm{O}_{4}\right)$ capped with ascorbic acid (SigmaAldrich) were synthesized by hydrothermal method. ${ }^{15}$ In brief, 0.54 g Ferric chloride anhydrous (LOBA Chemicals, 98\%) powder was dissolved in $25 \mathrm{ml}$ deionized water with stirring for five minutes at 
room temperature. $0.6 \mathrm{~g}$ Sodium carbonate (Sigma, 99\%) powder dissolved in $10 \mathrm{ml}$ deionized water is added to $\mathrm{FeCl}_{3}$ solution with continued stirring for 10 minutes, the solution turned viscous with brown color. Directly $0.12 \mathrm{~g}$ ascorbic acid was added with vigorous stirring for 15 minute, the color of solution turned black. The solution was transferred and sealed in a $50 \mathrm{ml}$ Teflon sealed autoclave. The autoclave was kept at $160{ }^{\circ} \mathrm{C}$ for $3 \mathrm{~h}$ before being cooled in air naturally. The final products were separated from the reaction medium by centrifugation. A Washing process including three cycles of centrifugation/ washing/ centrifugation steps using deionized water for two cycles and alcohol for the third one, then the obtained black powder was dried under vacuum oven at $60{ }^{\circ} \mathrm{C}$ for $12 \mathrm{~h}$. Characterization were performed by Transmission Electron Microscope (TEM, Tecnai G20, FEI, Netherlands), X-ray Diffraction (XRD, Xpert' Pro, PanAlytical, Netherlands) and Vibrating Sample Magnetometer (VSM, 7400, Lakeshore, US). All the Preparation and characterization processes were conducted at Nanotechnology and Advanced Materials Central Lab (NAMCL), Agriculture Research Center, Egypt.

\section{Preparation of Nano Iron fortified biscuits.}

Nano Iron fortified biscuits with three Iron concentration levels (10 ppm, $30 \mathrm{ppm}, 60 \mathrm{ppm}$ ) were prepared according to cookie method 1052-02 (AACC 2010) ${ }^{16}$ without ascorbic acid with slight modifications. In brief, the selected concentrations of Iron nanoparticles were dissolved in the amount of water used during blending process to ensure proper mixing of the iron nano particles with the flour. To achieve homogeneous flour and to ensure the level of fortification claimed, samples of the fortified flour were collected during blending and assayed for iron concentration. This process was carried out until the concentration of iron was similar in the sample taken from various section of the dough. Other dry ingredients (sugar, shortening, sodium carbonate and sodium chloride) and eggs were blended with the flour and dough thoroughly kneaded. Figure 1 illustrates the basic Nano iron fortified biscuit composition. The dough was then placed on a cutting board, rolled out until uniform thickness and textures were obtained. Biscuit cutter was used to cut the sheet of rolled dough into desired shapes and sizes, then baked in oven at $220{ }^{\circ} \mathrm{C}$ for about 15 min. the cooked biscuit was allowed to cool at room atmosphere, packed and store according to Kure el al. ${ }^{17}$ The finally, the final iron concentrations for all cooked biscuits groups were measured by Inductivity Coupled Plasma (ICP) instrument (PerkinElmer ICPOES: Optima 2000, Germany).

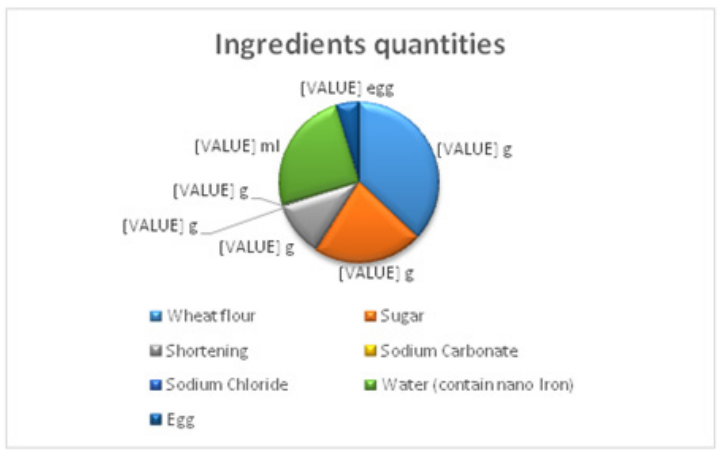

Figure I Ingredients composition of Nano iron fortified biscuits.

\section{Iron Deficiency Anemia Animals Model.}

Three weeks old Albino rats, weighing $70 \quad-80 \quad \mathrm{~g}$, were accommodated and adapted according to the NIH guidelines for animal health and accommodation ${ }^{18}$ at toxicology unit, regional Center for Food and Feed, Agricultural Research Center, Egypt. The laboratory animal facility is maintained under a 12 hour light/dark cycle at a temperature $(22 \pm 2){ }^{\circ} \mathrm{C}$, and relative humidity of $30-40 \%$. The animals were divided into five groups of seven rats each. Control negative group, control positive group, $10 \mathrm{ppm}$ nano iron group, 30 ppm nano iron group and $60 \mathrm{ppm}$ nano iron group. All groups were fed Iron deficient basal diet. Iron free basal diet was prepared to be used for rats feeding for two months to stimulate normal nutritional Iron deficiency anemic rats. The reference diet was formed of casein (casein ANRC $30 \mathrm{M}$ ) $10 \%$ supplemented with L-methionine $0.22 \%$ of the total solids of diet. The diet contained $10 \%$ sucrose, $69 \%$ maize starch, cellulose $5 \%$, maize oil $5 \%$, mineral blend $4.8 \%$, vitamin 0.8 $\%$, and choline chloride $0.2 \% .{ }^{19}$ The Chemicals used are analytical grads and the chemical analysis indicated that the basal diet contained less than $3 \mathrm{ppm}$ Iron of diet. After two months all animal groups were tested for Hemoglobin level and Red Blood Cells count. The iron free basal diet was replaced with the nano iron fortified Biscuits for the treated groups (10 ppm, $30 \mathrm{ppm}$ and $60 \mathrm{ppm}$ iron nanoparticles), while the control negative group was nourished the iron free basal diet for five weeks. Control positive group nourished ferric chloride fortified biscuit with $30 \mathrm{ppm}$ iron concentration. The designed period for treatment was five weeks

\section{Effect of Nano Iron Fortified Biscuits on Nutritional Quality of Protein}

In order to evaluate the effect of oral administration of nano iron fortified biscuits on the digestibility, absorbability, and the nutritional quality of protein in gut. Animal feeding experiment was constructed where the net protein utilization (NPU), Biological value (BV), and the true digestibility (TD) were estimated by Albino rats of the Sprague Dawley strain.

Five groups of five rats weighing between $75-80 \mathrm{~g}$ were weighted at the beginning of the experiment, the mean weight of the groups differed by no more than $0.5 \mathrm{~g}$. First group, control group, nourished protein diet only without oral administration of Iron nanoparticles through the experiment period. Second group, $\mathrm{FeCl}_{3}$ group, was nourished protein diet and orally administered $30 \mathrm{ppm} \mathrm{FeCl}$ solution. The other three groups were nourished protein diet and orally 1 administered $10 \mathrm{ppm}, 30 \mathrm{ppm}$ and $60 \mathrm{ppm}$ Iron nanoparticles. The oral administration was carried out once a day directly to an empty stomach cavity (before feeding) using gastric tube for injection.

The rats were housed individually in metabolic cages at $25^{\circ} \mathrm{C}$ of temperature and $50 \%$ of relative humidity. Daily food was restricted to $10 \mathrm{~g}$ of dry matter. Water was provided ad libitum. The experiment period was 9 days, with 4 days for adaptation. The oral administration stared after the adaptation period and was once a day before feeding of the rats and continued during 5 days balanced period. Feed residues, urine and faeces were collected during the 5 days balanced period. Urine and faeces were collected in $5 \%$ sulphoric acid and assayed for nitrogen quantification by Kjeldahl instrument (KjelMaster K-375, USA) for protein determination. True protein digestibility, biological value, and net protein utilization were calculated using the Thomas - Mitchell's equation. ${ }^{20}$ The reference protein diet was made with casein (casein ANRC $30 \mathrm{M}$ ) $10 \%$ supplemented with L-methionine $0.22 \%$ of the total solids of diet. The diet contained $10 \%$ sucrose, 69 $\%$ maize starch, cellulose $5 \%$, maize oil $5 \%$, mineral blend $4.8 \%$, vitamin $0.8 \%$, and choline chloride $0.2 \%{ }^{19}$ 


\section{Serum biochemical analysis}

Blood samples were collected at the end of designated period (five weeks) after treatment (three time points of analysis in total). Using biochemical analyzer (Merck MiroLab 200). General serum biochemical investigations were carried out; for liver functions, serum levels of Aspartate Transaminase (AST) and Alanine Transaminase (ALT) enzymes while, serum Urea and Creatinine for kidney function in addition to serum Total Cholesterol and Triglycerides.

\section{Hematological analysis}

Whole blood samples were collected on anticlotting agent and analyzed hematological indices, in particular, hemoglobin, erythrocytes, leukocytes and platelets using ABX animal cell counter.

\section{Histopathological analysis}

Rats were sacrificed at the designated period. Liver, spleen, heart, lungs, kidneys and intestine were removed from each animal and immersion-fixed in $10 \%$ formalin solution at room temperature. Autopsy samples ( $4 \mu$ tissue sections) were fixed in $10 \%$ formalin saline for twelve hours. Serial dilutions of alcohol (methyl, ethyl and absolute ethyl) were used. Specimens were cleared in xylene embedded in paraffin at 56 degree in hot air oven for twenty four hours. Paraffin bees wax tissue blocks were prepared for sectioning at 4 micron thickness by slide microtome. The obtained tissue sections were collected on glass slides, deparaffinized and stained by Hematoxylin and eosin (H \& E) and subsequently processed for histopathological examination under light microscope. ${ }^{21}$ Bone marrow smears were prepared by aspiration from femur of decapitated rats using clean syringes. Then Bone marrow was mixed with a drop of the serum of the same animal species using vortex mixing for 30 second. This step aims to facilitate the preparation of uniformed bone marrow smear. A smear was prepared by spreading a drop of the resulting suspension on a clean dry microscopic slide to form a thin bone marrow film. The film was left to dry in air for five minutes then fixed with methanol for ten minutes, dry in air again and stained with Giemsa stain for sixty minutes. The resultant film was rinsed under running tap water, dried in air and examined under light microscope..$^{22}$

\section{Statistical analysis}

The collected data were subjected to analysis of variance in one and two ways (ANOVA) by aids of Origin 10 and excel software working under windows.

\section{Results \& discussion}

\section{Iron nano particles preparation \& characterization}

Iron nanoparticles (Magnetite, $\mathrm{Fe}_{3} \mathrm{O}_{4}$ ) were prepared according to a previously described method. TEM image showed spherical shaped particles with average size of $20 \pm 5.0 \mathrm{~nm}$ as illustrated in Figure 2a. For phase analysis, XRD patterns for the as-prepared iron nanoparticles is shown in Figure 2b. Characteristic pattern peaks are observed at $2 \theta$ values of $30.11^{\circ}(220), 35.47^{\circ}(311), 43.05^{\circ}(400), 56.94^{\circ}(511)$ and $62.51^{\circ}(440)$ in the pattern consistent with the cubic phase spinel structure $\mathrm{Fe}_{3} \mathrm{O}_{4}$ (JCPDS: No. 04-006-6497). The estimated crystal size using Scherrer's equation was $25 \mathrm{~nm}$, the obtained results were consistent with the previously published literatures. ${ }^{23,24}$

\section{Nutritional evaluation}

Effect on growth rate: There were no abnormal clinical signs observed on the laboratory animals during the feeding with all doses of the nano iron fortified biscuits and did not induce any apparent toxicity. During the study periods, nourishment with nano iron diets for five weeks did not cause any adverse effects on growth rate. Increased body weight gain was recorded for nano iron groups compared to $\mathrm{FeCl}_{3}$ group and control one as illustrated in Figure 3. Furthermore, it is very important to evaluate the reason of increasing body weight gain with increasing the nano iron concentration by studying the effect of nano iron fortified biscuits on Nutritional Quality of Protein that is done as a following

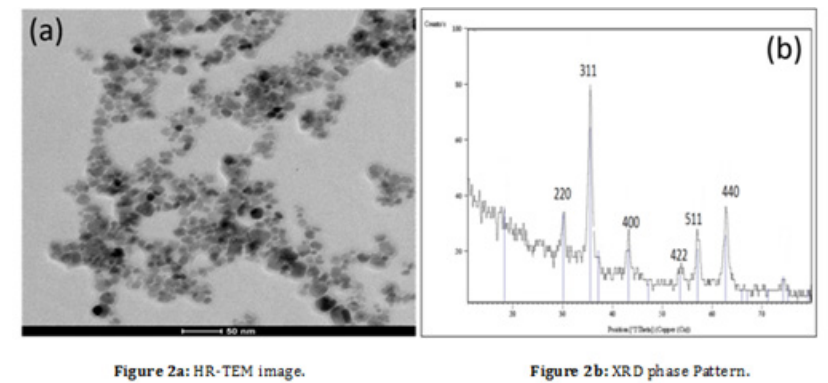

Figure 2 Characterization of Iron nano particles.

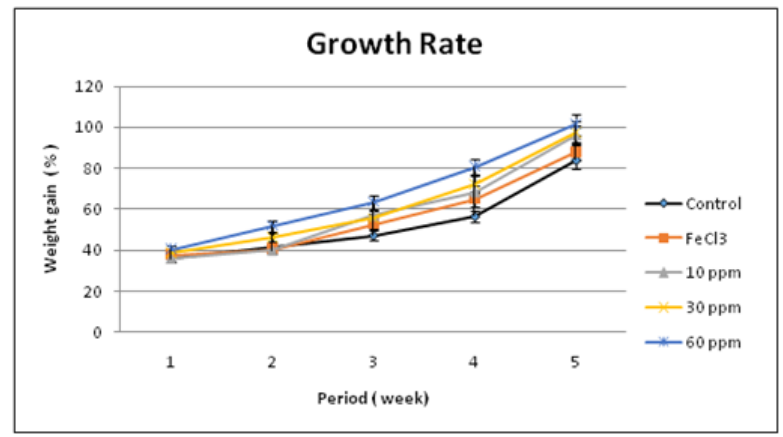

Figure 3 Effect of Nano iron fortified biscuits on growth rate of treated rats compared to the controls.

Effect on nutritional quality of protein: To evaluate the effect of oral administration of Iron Fortified Biscuits on the digestibility, absorbability, and the nutritional quality of protein diet. Animal feeding experiment was constructed where the net protein utilization (NPU), Biological value (BV), and the true digestibility (TD) were evaluated Albino rats of the Sprague Dawley strain. Table 1 summarized the net obtained results. These results indicates that, there was no significant increase in the values of the True Digestibility (TD), Biological Value (BV) and Net Protein Utilization (NPU) between the nano iron diet nourished groups at the chosen doses compared to $\mathrm{FeCl}_{3}$ and control groups. This explain the increased growth rate with increasing the nano iron concentration as a result of the increase of the absorbability and bioavailability of the protein diet within the intestine.

Table I Effect of Nano iron diet on the nutritional quality of protein

\begin{tabular}{llll}
\hline Treatment & $\begin{array}{l}\text { True } \\
\text { Digestibility } \\
\text { (TD) }\end{array}$ & $\begin{array}{l}\text { Biological } \\
\text { Value (BV) }\end{array}$ & $\begin{array}{l}\text { Net Protein } \\
\text { Utilization } \\
\text { (NPU) }\end{array}$ \\
\hline Control & $90.12 \pm 1.0$ & $80.322 \pm 1.1$ & $70.149 \pm 1.2$ \\
FeCl $_{3}$ & $91.234 \pm 1.1$ & $81.023 \pm 1.2$ & $71.228 \pm 1.3$ \\
I0 ppm Nano Iron $93.875 \pm 1.3$ & $83.656 \pm 1.4$ & $75.345 \pm 1.5$ \\
$\mathbf{3 0}$ ppm Nano Iron $95.121 \pm 1.2$ & $85.84 I \pm 1.5$ & $80.332 \pm 1.6$ \\
60 ppm Nano Iron $97.543 \pm 1.6$ & $89.654 \pm 1.4$ & $86.081 \pm 2.1$ \\
\hline
\end{tabular}

Histopathological examination of the intestine of rats nourished nano iron diet gave the undoubted answer. Figure 4, histopathological examination showed branching of the intestinal were induced spatially for $30 \mathrm{ppm}$ and $60 \mathrm{ppm}$ nano iron nourished groups which in turn increase the area of absorption and explaining the improvement of nutritional quality of the protein in gut and hence enhanced growth rate. 


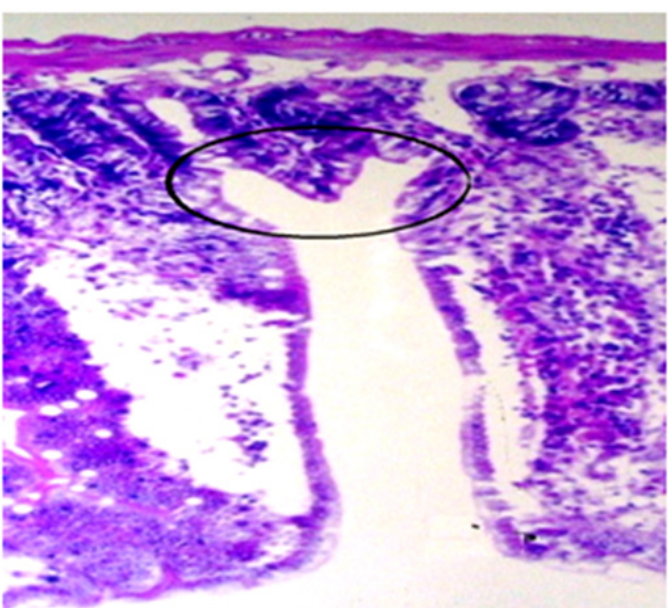

Figure 4 Histopathological examination of intestinal villi of nano iron nourished group showing induced villi branching.

\section{Effect on iron deficiency anemia (IDA)}

Iron deficiency anemia was by feeding the experimental rats iron free basal diet until the mean blood hemoglobin concentration $(\mathrm{Hb})$ and Red Blood Cells count (RBCs) were $9.8 \pm 1.2 \mathrm{~g} / \mathrm{dl}$ and $3.4 \pm$ $0.9 \times 10^{6} / \mathrm{mm}^{3}$ respectively. Treatment groups were divided into three levels of nano iron fortified biscuits, (10 ppm, $30 \mathrm{ppm}$ and $60 \mathrm{ppm}$ ) and one level of Ferric chloride fortified biscuits $\left(\mathrm{FeCl}_{3}\right)$, (30 ppm) in addition to untreated control group (nourished iron free diet). Daily nourishment were carried out for five weeks then Hematological tests were performed, (Figure 5a \& 5b) Hemoglobin concentration and erythrocytes count as indicator for iron deficient anemia recovery. For the tree levels of nano iron fortified diet; 10 ppm, $30 \mathrm{ppm}$ and $60 \mathrm{ppm}$, Hemoglobin concentration increased to be $14.6 \pm 1.1 \mathrm{~g} / \mathrm{dl}, 16.7 \pm 1.6 \mathrm{~g} / \mathrm{dl}$ and $18.2 \pm 2.1 \mathrm{~g} / \mathrm{dl}$ respectively. While for RBCs count increased to be $6.7 \pm 1.4 \times 10^{6} / \mathrm{mm}^{3}, 7.3 \pm 1.6 \times 10^{6} /$ $\mathrm{mm}^{3}$ and $7.8 \pm 1.8 \times 10^{6} / \mathrm{mm}^{3}$, respectively. The increase in both $\mathrm{Hb}$ concentration and RBCs count might be attributed to the stimulation of erythropoiesis process by nano iron formula as a result of efficacy of the Nano size for intestinal absorption and cellular uptake on addition to increase the nutritional quality of proteins in gut. While the group treated with $\mathrm{FeCl}_{3}$ fortified biscuits, $\mathrm{Hb}$ concentration and RBCs count increased to be $12.7 \pm 1.4 \mathrm{~g} / \mathrm{dl}$ and $5.2 \pm 1.8 \times 10^{6} / \mathrm{mm}^{3}$, respectively, indicating hypochromic anemia. All the obtained results were compared to the control untreated group. These results confirm the success of the prepared nano iron fortified biscuits to be used at least for management and control Iron Deficiency anemia. Leukocytes and platelets blood indices were tested for any abnormal deviations. (Figure $5 \mathrm{c} \& 5 \mathrm{~d}$ ) indicate no abnormal changes were observed in all treated groups compared to the control one. Normal leukocyte counts reflected the non-immunogenic nature of the used iron forms while the normal platelets counts indicated normal factionalized platelets biosynthesis process.

\section{Toxicological evaluation}

Although the nutritional efficiency of the nano iron fortified biscuits for management and control of Iron Deficient Anemia was successfully evaluated, but the potential toxicity must be evaluated. In order to obtain detailed toxicity data, at the end of each designated period after five weeks treatment), clinical biochemistry analysis and histological examination of various tissue organs including the Liver, Spleen, Heart, Lungs, Kidneys, Intestine and Bone Marrow for all experimental groups.
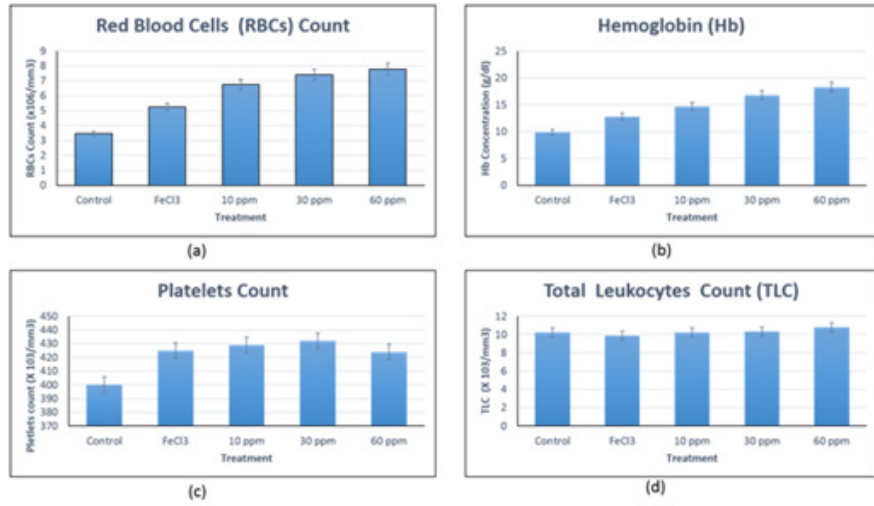

Figure 5 Hematology indices.

Figure5a Red Blood Cells (RBCs) count.

Figure 5b Hemoglobin Concentration.

Figure 5c Platelets count.

Figure 5d Total leukocytes count.

\section{Clinical biochemistry}

Serum Liver function tests (AST and ALT) were performed and showed normal levels for all treated groups compared to control group except for $60 \mathrm{ppm}$ nano iron group showed a slight increase of AST and ALT activity, (Figure $6 \mathrm{a} \& 6 \mathrm{~b}$ ), as a result of the slight hepatocytes inflammatory cell infiltration observed from the histopathological examinations of liver of $60 \mathrm{ppm}$ nano iron group. For renal functions testes, serum Creatinine and Urea concentrations were measured for all groups and the results were in the reference range indicating the nano iron diets did not affect the glomerular filtration rate of the kidneys of treated rats during the studied periods compared to control groups, (Figure 6c \& 6d). Concerning lipid metabolic effects, a mild elevation in serum total cholesterol level was observed with increasing nano iron dose compared to the control groups. While a mild decrease in mean serum Triglycerides levels was observed especially with high MNPs doses, (Figure 6e \& 6f). Also because of the complicated regulatory factors controlling lipid metabolism, it was difficult to explain the mild hypercholesterolemia and mild hypotriglyceridemia.

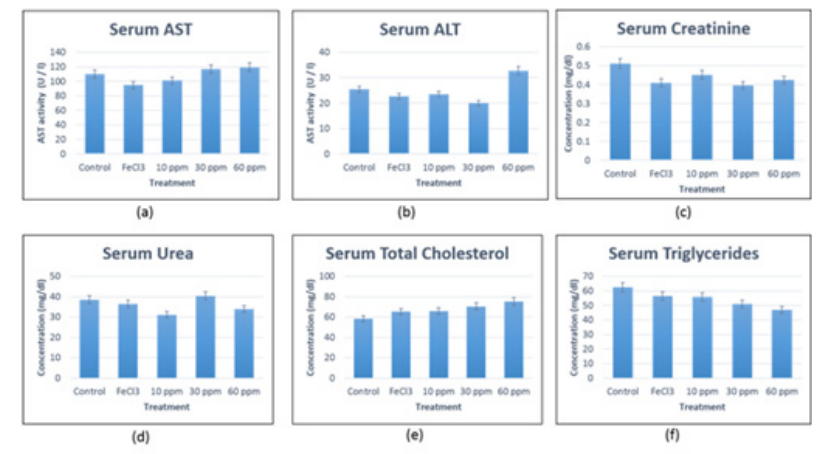

Figure 6 Clinical biochemical analysis.

Figure 6a Serum AST Isevels.

Figure 6b Serum ALT levels.

Figure 6c Serum Creatinine concentration.

Figure 6d Serum Urea Concentration.

Figure 6e Serum Total Cholesterol concentration.

Figure 6f Serum Triglycerides concentration. 


\section{Histopathology examination}

At the end of the designed experiment period, rats of all groups were sacrificed and the internal organs were anatomized, the selected organs were Liver, Spleen, Heart, Lungs, Kidneys, Intestine and Bone Marrow. Figure 7 summarized the main histopathological examinations. Liver showed no abnormal histopathological alteration with normal of central vein $(\mathrm{CV})$ and surrounding hepatocytes $(\mathrm{H})$ within all treated groups except the $60 \mathrm{ppm}$ Nano Iron treated group which showed mild inflammatory cells infiltration, explaining the mild elevation of the liver enzymes activities (AST and ALT). Similar observation for Spleen was recorded where the normal histological structure of white pulp lymphoid follicles (W) and red pulps with sinusoids (R), except $60 \mathrm{ppm}$ Nano Iron treatment which showed lymphoid depletion in white pulp might be as a result of inflammatory response. Heart show no histopathological alternation observed, Where normal histological structure of the Pericardium (P) and Myocardium (M) for all treated groups. Lungs of all groups showed normal histological structure of the Bronchus (B), air alveoli (V) and blood vessel (BV) except for 60 ppm Nano Iron dose group, mild peribronchial and perivascular inflammatory cells infiltration was observed. Kidneys showed the normal histological structure of the glomeruli $(\mathrm{G})$ and renal tubules (RT).

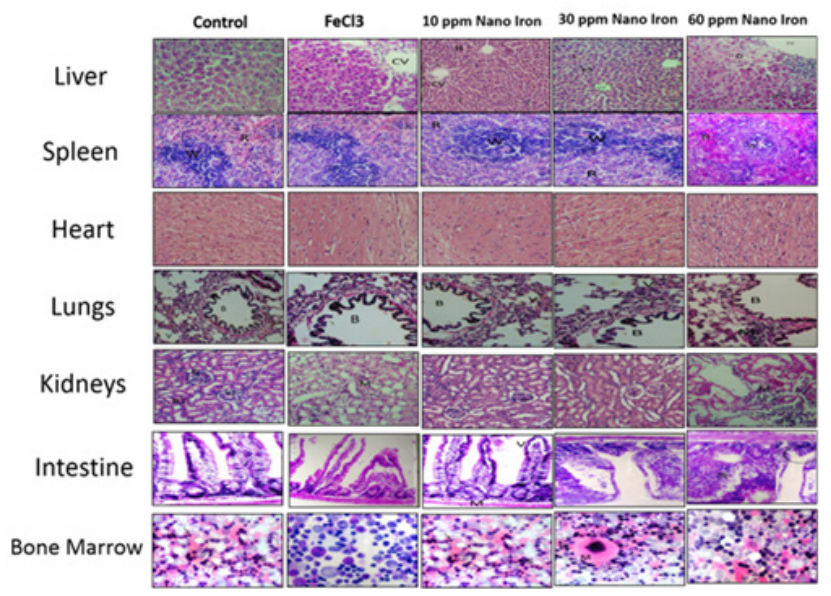

Figure 7 Histopathological Microscopic Examination of the tested tissue organs, stained with Hematoxylin and Eosin (H\&E) stains and imaged under $40 \times$ magnification.

For all groups except the $60 \mathrm{ppm}$ nano Iron group showed mild inflammatory cells infiltration in between the degenerated renal tubules. Histopathological examination of the intestine showed normal histological structure of the villi and muscularis for all groups. Moreover, branching of the villi was observed for $30 \mathrm{ppm}$ and $60 \mathrm{ppm}$ Nano Iron groups revealing the efficiency of Nano iron to improve the bioavailability abd absorptivity inside the intestine. This observation explained why the iron in nano form is more effective for treatment iron deficiency anemia in a very short time compared to the conventional iron forms. Bone Marrow smears of all animal groups showed no histopathological alternation observed where normal megakaryocyte and erythroid islands and normal leucocytes was observed compared to the control group. From the toxicological point of view, the inflammatory cells infiltration observed in high dosed $60 \mathrm{ppm}$ Nano iron group with liver, kidney and lung in addition to lymphoid depletion in white pulp of might be attributed to the normal nonspecific immunological response against high dose concentration irrespective to its nano structural form.

\section{Conclusion}

Nano iron fortified biscuits was used to as a food supplement to manage and control iron deficient anemia in rats. The nutritional evaluation revealed that, enhanced growth rate was recorded and the nutritional quality of protein was increased including absorptivity, bioavailability and net protein utilization. Great success was achieved with the management and control of iron deficiency anemia in experimental animal model, where not only complete recovery form the anemic state to the normal level within five weeks but improved Hemoglobin concentration and Red Blood Cells count to the high normal level within a very short time compared to the commercial routes. From the toxicological evaluation, all used nano iron doses (10 ppm, $30 \mathrm{ppm}$ and $60 \mathrm{ppm}$ ) prepared by this work did not cause any apparent toxicity (no physical and behavioral abnormalities or morbidity or mortality) and LD50 cannot be established where no mortality during the designed experiment period. From clinical blood biochemical evaluations and histopathological examination, concentrations of $10 \mathrm{ppm}$ and $30 \mathrm{ppm}$ nano iron fortified biscuits are the more reliable and safe compared to the $60 \mathrm{ppm}$ diet concentration. The present work recommend the use of $10 \mathrm{ppm}$ nano iron fortified biscuits for mild iron deficiency anemia and the $30 \mathrm{ppm}$ for more sever one to manage and control Iron deficient anemia and extra toxicological testing are still required, such as immunogenic test, coagulation profile, Ferritin, TIBC, ...etc.

\section{Acknowledgments}

None.

\section{Conflictss of interest}

None.

\section{References}

1. WHO. Second report on the world nutrition situation- volume 1: Global and regional results. Geneva: ACC/SCN WHO, Switzerland. 1992.

2. Tapiero H, Gate L, Tew KD. Iron: deficiencies and requirements. Biomed Pharmacother. 2001;55(6):324-332.

3. Cook JD. Diagnosis and management of iron-deficiency anaemia. Best Pract Res Ha. 2005;18(2):319-332.

4. ACC/SCN Sub-Committee on Nutrition. 4th Report on the World Nutrition Situation: Nutrition thought the life cycle. United Nations, Geneva, Switzerland. 2000.

5. Lozoff B, Jimenez E, Hagen J, et al. Poorer behavioral and developmental outcome more than 10 years after treatment for iron deficiency in infancy. Pediatrics. 2000;105(4):E51.

6. Lozoff B, De Andraca I, Castillo M, et al. Behavioral and developmental effects of preventing iron-deficiency anemia in healthy full-term infants. Pediatrics. 2003;112(4):846-854.

7. Haas JD, Brownlie TT. Iron deficiency and reduced work capacity: a critical review of the research to determine a causal relationship. $J$ Nutr. 2001;131(2S-2):676S-688S.

8. de Silva A, Atukorala S, Weerasinghe I, et al. Iron supplementation improves iron status and reduces morbidity in children with or without upper respiratory tract infections: a randomized controlled study in Colombo, Sri Lanka. Am J Clin Nutr. 2003;77(1):234-241.

9. Maniatis A. The role of iron in anaemia management: can intravenous iron contribute to blood conservation? ISBT Science Series. 2008;3(1):139-143.

10. Fantini, Ana Paula, Canniatti-Brazaca, et al. Ciencia e Tecnologia de Alimentos (Campinas, Brazil). 2008;28(2):435-439.

11. Hurrell R. Iron. In: Hurrell R (Ed.), The Mineral Fortification of Foods. Leatherhead : Leatherhead Publishing, UK. 1999;pp.54-93. 
12. Murray-Kolbe LE, Beard J. Iron. In: Coates PM, et al. (Eds.), Encyclopedia of Dietary Supplements (2nd edn.), Informa Healthcare, London, UK. 2010;pp.432-438.

13. Taher AS, Mona BM, Hosam K, et al. Magnetite nano particles as a single dose treatment for iron deficiency anemia. WIPO Patent Application WO/2010/034319. 2010

14. Hanaa HE, Al sayed AM, Eman EA, et al. Treatment of anemia progression via magnetite and folate nano particles in-vivo. ISRN Nanotechnology. 2014:13.

15. Shouhu Xuan, Lingyun Hao, Wanquan Jiang, et al. Preparation of water-soluble magnetite nano crystals through hydrothermal approach. Journal of Magnetism and Magnetic Materials. 2007;308(2):210-213.

16. AACC International. Approved Methods of Analysis (11th edn). Method 10-52-02 Baking quality of cookie flour-Micro Method, AACC International: St. Paul, Minnesota, USA. 2010.

17. Kure OA, Bahago EJ, Daniel EA. Studies on the proximate composition and effect of flour particle size on acceptability of biscuit produced from blends of soyabeans and plantain flour. Namida TechScope J. 1998;3:17-21.

18. US department of health and human services. Guide for the Care and use of Laboratory Animals. NIH publication, No. 1985;86-23.
19. Jenny Ruales, Yolanda de Grijalva, Patricio Lopez-Jaramillo, et al. The nutritional quality of an infant food from quinoa and its effect on the plasma level of insulin-like growth factor-1 (IGF-1) in undernourished children. Int J Food Sci Nutri. 2002;53(2):143-154.

20. Eggum BO, Hansen I, Larsen T. Protein quality and digestible energy of selected food determined in balance trials with rats. Plant Foods Hum Nutr. 198939(1):13-21.

21. Levison DA. "Theory and Practice of Hitological Techniques". In: Banchroft JD \& Stevens A (4th edn.), Churchil Livingstone, Edinburgh, UK, pp. 766. 1996.

22. Hoffbrand AV, Pettit JE. "Essential Haematology". (3rd edn.), Black well scientific publication, Oxford, UK. 1992.

23. Bassiony H, Sabet S, Salah El-Din TA, et al. Magnetite Nano particles Inhibit Tumor Growth and Up regulate the Expression of P53/P16 in Ehrlich Solid Carcinoma Bearing Mice. PLoS One. 2014;9(11):e111960

24. Mohamed A Farghali, Taher A Salah El-Din, Abdullah M Al-Enizi, et al. Graphene/ Magnetite Nano composite for Potential Environmental Application. Int J Electrochem Sci. 2015;10:529-537. 